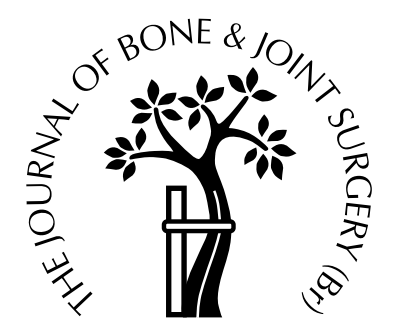

\title{
Annotation
}

\section{THE TRAUMA CENTRE: NOW AND IN THE FUTURE}

\author{
N. P. Haas
}

From Humboldt University, Berlin, Germany

(Printed with permission of EFORT. The original version of this article appears in

European Instructional Course Lectures Vol. 5, 2001.)

In 1904 Mercedes-Benz ordered a study to investigate the future of the automobile market. The prediction was that no more than 70000 new cars would be needed each year. It was thought that a technician would be required for every car to facilitate its use, and there were then only 70000 technicians in the world. ${ }^{1}$

In 1980 the IBM board discussed whether the personal computer (PC) or the megacomputer would be the future requirement. They agreed that ordinary people would not be able to use such a sophisticated machine as a PC. ${ }^{1}$

These examples show the difficulty in making predictions. Nevertheless, we have to think about the future since we live in a world of such rapid change. With this in mind we have to examine the demands on and need for trauma centres in Europe. We need to ensure that they bring highquality care in an economical way.

In spite of the economic pressures and rising costs, European citizens expect a high level of efficiency in modern medicine. Trauma centres will be judged by their ability to manage polytrauma. This is of a high standard in Germany and is based on a comprehensive system for the transport of the injured. ${ }^{2,3}$

\section{The frequency of polytrauma in Germany}

Between seven and eight million accidents occur in Germany each year; $60.5 \%$ are in the home or at sport, $27 \%$ at work, $8.5 \%$ in road-traffic accidents and $4 \%$ are due to direct violence or suicide.

Traffic accidents cause the most severe injuries. A person is injured in a traffic accident every 15 seconds. More than 395000 accidents resulting in injury occurred in 1999, 7749 people died $(0.6 \%$ less than 1998) and 521000 were injured. More than $70 \%$ of polytrauma was caused by traffic accidents followed by those at home (20\%) and at work $(10 \%) .{ }^{4}$ The number of patients with polytrauma can only be estimated because there is not a complete register.

N. P. Haas, MD, Professor

Clinic for Trauma and Reconstructive Surgery, Charité, Humboldt University, Berlin, Germany

(C2002 British Editorial Society of Bone and Joint Surgery

0301-620X/02/513599 \$2.00

J Bone Joint Surg [Br] 2002;84-B:627-30.
Registration depends on the severity of injury and the scoring system used to describe it. The 'Polytrauma Schlüssel' (PTS) ${ }^{5}$ is established in German-speaking countries, whereas the 'Injury Severity Score' (ISS) ${ }^{6}$ is predominantly used in the English-speaking world.

The number of patients with polytrauma who have a PTS score of III or IV in Germany is estimated at 20000 per year. ${ }^{7}$ This rises to 100000 if the PTS score II is included. ${ }^{8}$ These figures correlate with police statistics concerning persons injured in traffic accidents and treated in hospitals.

The combination of accidents at home and work, the increasing number of acts of violence and attempts at suicide produce about 32500 patients with polytrauma who have a PTS score of III or IV in Germany each year.

\section{Trauma centres in Germany}

The treatment of polytrauma is carried out in hospitals with different levels of facility. A profile of the requirements for trauma departments in German hospitals is found in the recommendations of the German Society of Traumatology. ${ }^{9}$ The definitions and needs follow the guidelines of the German Society of Traumatology and the American College of Surgeons (ACS) Committee on Trauma. ${ }^{10}$

We have three categories of hospitals for trauma in Germany. Those with the lowest grade of facilities correspond to the American trauma centre level IV. The head of the department should be a surgeon who specialises in traumatology and there must be a recognised department of surgery. The ability to undertake operations throughout 24 hours is required.

The hospital on the next higher level, similar to the ACS trauma level III, needs an independent department for traumatology with its own budget and an autonomous service plan. It must have the capacity for 24-hour trauma surgery, its own emergency room, separate beds in an intensive-care unit and full access to the system for the primary evacuation of injuries.

Hospitals at the highest level, similar to ACS level II or I, provide a 24-hour service with full specialist cover. All departments and subspecialities are available.

An overview of the different categories is shown in Table 
I. It describes the different roles played by the varying types of hospital in the treatment of polytrauma. It shows that hospitals at level III or IV should only stabilise the vital parameters of the patient who should then be transferred to the next most suitable hospital. Level-II hospitals should only undertake measures which are within their ability. The level-I trauma centre must guarantee the availability of all personal and structural requirements for the full treatment of polytrauma.

\section{Economic aspects of trauma}

The costs of the treatment and rehabilitation of patients after injury are high and must be appreciated when considering the economics of a trauma centre. The national accident insurance companies insure 29.7 million people. The total expenses including follow-up treatment, pensions and indemnity are 17.6 billion DM for victims of accidents. ${ }^{11}$ Although under $11 \%$ of the patients have multiple injuries they are responsible for $25 \%$ of the total expenditure, ${ }^{12}$ approximately 4.4 billion DM.

For the German economy the consequences of accidents produce an annual loss of 620000 living years and 520000 working years. ${ }^{13}$

The victim of an accident costs an average of 98000 $\mathrm{DM}$, which increases to up to $500000 \mathrm{DM}$ with lifelong disablement. ${ }^{14}$ If we consider the 32500 multiply injured patients and calculate that 15000 have consequent problems and 17500 do not, the cost to the public economy is nearly 10 billion DM per year.

There have been three attempts at calculating the primary costs of managing a polytrauma patient in Germany. Ruch-

Table I. Requirements for hospitals treating severely injured persons: +, necessary; (+), desirable; and -, not necessary

\begin{tabular}{llll}
\hline $\begin{array}{l}\text { Criteria for the } \\
\text { departments }\end{array}$ & Level I or level II & Level III & Level IV \\
\hline Independent & + & + & - \\
Trauma surgery/surgery & + & + & + \\
Neurosurgery, etc & + & $(+)$ & - \\
Heart surgery & + & - & - \\
Anaesthesia & + & + & + \\
Radiology & + & + & $(+)$ \\
Urology & + & $(+)$ & - \\
Replantation medicine & + & - & - \\
Complete infrastructure & + & $(+)$ & - \\
\hline
\end{tabular}

Table II. Costs of treatment (DM) of all emergency patients (marginal costs in parentheses)

\begin{tabular}{ll}
\hline Emergency room & $2104000(600000)$ \\
Operation unit & $5000000(3044000)$ \\
Intensive-care unit & $4560000(2400000)$ \\
Normal ward & $4824000(1132000)$ \\
\hline
\end{tabular}

holtz et al $^{15}$ found that the average cost to be $64000 \mathrm{DM}$ whereas Kinzl ${ }^{16}$ quotes a figure of 62000 DM and Obertacke et $\mathrm{al}^{17} 104000$ DM. When the marginal costs are included the figure rises to between 100000 and 150000 DM per person. Studies from Munich ${ }^{15}$ and $\mathrm{Ulm}^{16}$ have divided the costs into the emergency room (5\%), the operating room $(20 \%)$, intensive care $(65 \%)$ and the ward (10\%).

\section{Economic aspects of a trauma centre}

The costs of a single trauma centre can be illustrated by those of the Charité Campus Virchow at the Humboldt University, Berlin.

Between May 14, 1995 and May 14, 1996, 17211 victims of an accident received clinical treatment; 2077 had been brought in by ambulance, $1186(53.7 \%)$ as an emergency. Of those admitted as emergencies, $154(13 \%)$ had an ISS score $>16$. There were 104 patients $(8.8 \%)$ with a PTS score of III or IV. Basing the calculation of primary costs for multiply injured persons on the number of severely traumatised patients and the primary estimates as stated by Ruchholtz et $\mathrm{al}^{15}$ at $64000 \mathrm{DM}$, the cost of primary treatment for a multiply injured patient was $104 \times 64000$ $=6656000 \mathrm{DM}$.

It is important to look at this figure in relation to the primary costs of clinical treatment for all emergency patients, which is based on the total costs of the emergency room, operating unit, intensive-care unit and the normal ward as shown in Table II.

These figures include the primary costs of treatment of all trauma patients, of medical equipment and those for other departments. The amounts for the buildings, their maintenance, cleaning, catering and management are not included.

The primary costs for all forms of clinical treatment for both elective and emergency patients are assessed by a factor for their distribution. The primary costs of the trauma centre were weighted as follows. For the emergency room, with 17000 patients per year for ambulant treatment, we define 0.7 as the factor, because the costs for patients who were admitted, especially those with multiple injuries, take the major part. For the operating theatre we have chosen a factor of 0.6 since emergency operations are more expensive than elective procedures. The intensive-care unit does not deal with the immediate postoperative patient, and hence the costs are mostly for emergency patients, particularly those with multiple injuries. We therefore allocated a factor of 0.9. Because of the increased time spent by emergency patients in hospital we calculated the cost factor for the normal ward as 0.65 , slightly higher than the average of $53.7 \%$.

Taking these factors into account the primary costs of the clinical treatment of emergency patients at the trauma centre Charite Campus Virchow are shown in Table III. These amount to nearly 12 million DM. The costs for the 
Table III. Primary costs (DM) of treatment for emergency patients at the trauma centre of Charité Campus Virchow

\begin{tabular}{lr}
\hline Emergency room & $2104000 \times 0.7=1472800$ \\
Operation unit & $5000000 \times 0.6=3000000$ \\
Intensive-care unit & $4560000 \times 0.9=4104000$ \\
Normal ward & $4824000 \times 0.65=3135600$ \\
Total & 11712400 \\
\hline
\end{tabular}

Table IV. The infrastructure for the treatment of polytraumatised patients in Europe

\begin{tabular}{lccll}
\hline Country & $\begin{array}{l}\text { Inhabitants } \\
\text { (million) }\end{array}$ & $\begin{array}{l}\text { Area } \\
\left.\text { (km }^{2}\right)\end{array}$ & $\begin{array}{l}\text { Trauma } \\
\text { centres }\end{array}$ & $\begin{array}{l}\text { Polytrauma } \\
\text { patients treated } \\
\text { per year }\end{array}$ \\
\hline Germany & 81.0 & 356970 & 90 & 100 to 200 \\
Austria & 8.0 & 83850 & 12 & 100 to 200 \\
Switzerland & 7.1 & 41290 & 7 & $6<100,1>200$ \\
France (Paris) & 14.0 & 10000 & 15 & 100 to 200 \\
Finland & 5.1 & 305470 & 5 & 100 to 200 \\
Sweden & 8.8 & 410928 & 7 & 100 to 200 \\
The Netherlands & 15.4 & 33920 & 12 & $4<100,8>100$ \\
Portugal & 10.5 & 91649 & 4 & $>1000$ (Lisboa) \\
Croatia & 4.7 & 56410 & 4 & $>200$ \\
\hline
\end{tabular}

primary treatment of polytrauma patients were calculated as 6.6 million DM, $56.8 \%$ of the overall sum. To calculate the total costs of a trauma centre, allowance must be made for depreciation of medical equipment and buildings, maintenance and cleaning, catering and laundry. The department of finance has the job of identifying these additional figures but they are probably equal to the primary costs, giving an overall figure of 24 million DM. From these statistics we can calculate the running costs for the treatment of polytrauma. The following formula was developed:

whole primary treatment costs $\times 0.7-$ costs for objects $\times 0.9$

A major part of the costs is for staff. Much of their working time can be used for the treatment of outpatients; their presence at the hospital is always necessary in order to treat polytrauma as required.

\section{Analysis of German and European trauma centres (Table IV)}

When planning centres for the treatment of polytrauma, the overall population must be considered together with its density and geographical spread.

There are about 90 level-I trauma centres in Germany corresponding to American level-I or level-II centres. Germany has a population of 81 million occupying an area of $356000 \mathrm{~km}^{2} .{ }^{18}$ The average centre receives between one and two hundred patients with polytrauma per year. Theoretically, each of the 90 trauma level-I centres should treat 361 such patients per year, but only about half are treated in a centre of the highest level. This trend can be seen elsewhere in Europe. For instance, in Austria between 100 and 200 patients are seen in each level-I centre per year. There are 12 centres and 8 million inhabitants. In Switzerland which has 7.1 million inhabitants, there are seven trauma centres, but six treated less than 100 patients per year and only one more than 200. In the Paris area of France there are 15 trauma centres, four of level-I and 11 of level-II for 14 million inhabitants. There is a similar relation of population and trauma centres in the sparsely populated Scandinavian countries.

In Portugal, with a population of 10.5 million, there are only four trauma centres but that in Lisbon treats 1300 patients per year.

In The Netherlands the figures correspond to the European average, while in Croatia there are four centres for 4.67 million people.

Collection of these data has demonstrated the lack of centres which undertake proper documentation of trauma care in Europe. Such organisations are necessary in order to plan the development of the appropriate management of trauma. On the basis of our data we found a requirement for one level-I centre per one million population.

\section{The air-rescue system}

The facilities for the transport of the injured to a trauma centre require careful consideration. In Germany in 1994 there were 854 locations for emergency physicians and 51 bases for air rescue. These were co-ordinated by 442 central rescue offices involving both private and public organisations. A rescue helicopter with an average flight radius of $50 \mathrm{~km}$ can service an area of $7850 \mathrm{~km}^{2}$. The 51 rescue helicopter centres cover nearly the whole area of Germany. In Switzerland, because of the high mountains, there are 15 helicopters in operation although, theoretically, only six would be needed to cover the area.

The need for the availability of a secondary system of helicopters for the transfer of severely injured patients from small hospitals to level-trauma centres is increasing.

\section{European trauma centres in the next century}

In order to describe the future of trauma centres in Europe it is helpful to include the American experiences and figures. The Committee on Trauma of the ACS has defined the categories of I to IV of trauma centres and the number of patients which they should treat. They considered that on the basis of one level-I centre per million inhabitants, each would treat between 800 and 1000 severely injured patients per year. Each trauma surgeon would deal with about 50 patients per year, a minimum of one per week. This number of cases is necessary to maintain proper skills.

An overall balance of quality of cases related to costs suggests that an average of 300 to 400 patients per centre per year would be ideal. This would give one multiply injured patient per day at each centre. However, the reality 
is far from this ideal situation. In Europe more than half of all patients with polytrauma were treated in level-III or level-IV centres. The first phase of treatment in the emergency room costs only about $5 \%$ of the whole costs. The major part of the costs is the intensive-care unit and the many operative procedures. Costs increase with permanent improvement in the quality of patient care. The overall costs of treatment can be made less by avoiding the entire management of polytrauma at level-III or level-IV centres. In order to guarantee the treatment of severely injured persons at a high-quality level in an economical way it is necessary that a hospital of a lower level does the primary treatment, stabilises the vital parameters and then transfers the patient to the trauma centre at the next level.

\section{Outlook}

Accepting the need for one level-I trauma centre per one million people, there are already enough centres for the population across Europe. However, too many patients are treated in hospitals which are inappropriate. We need a further shift in favour of level-I trauma centres, with one per one million inhabitants treating 300 to 400 patients per year. The ACS guidelines demand that a trauma surgeon treats 50 patients with polytrauma per year. Hospitals at trauma level III or level IV should treat the severely injured patients primarily, stabilise the vital functions and then transfer the patient to a level-I or level-II centre. The infrastructure for the treatment of polytrauma is available in Europe. We should concentrate on the better use of the given resources and the permanent development of a system for the treatment of these patients.

\section{References}

1. Kroy W. The business of the future, 1995.

2. Trunkey DD. Trauma. Accident and intentional injuries account for more years of life lost in the US than cancer and heart disease: among the prescribed remedies are improved preventive efforts, speedier surgery and further research. Sci Am 1983;249:28-35.

3. Tscherne H, Regel G, Sturm JA, Friedl HP. Schweregrad und Prioritäten bei Mehrfachverletzungen. Chirurg 1987;58:631-40.

4. Heiss MM, Jauch K-W, Madler C. Polytrauma. In: Madler C, Jauch K-W, Werdan K, eds. Das NAW Buch. München: Urban \& Schwarzenberg, 1994:570-86.

5. Oestern HJ, Tscherne H, Sturm J, Nerlich M. Klassifizierung der Verletzungsschwere. Unfallchirurg 1985;88:465-72.

6. Baker SP, O'Neill B, Haddon W, Long WB. The injury severity score: a method for describing patients with multiple injuries and evaluating emergency care. J Trauma 1974;14:187-96.

7. Ott R, Holzer U, Spitzenpfeil E, et al. Quality of life after survival of severe trauma. Unfallchirurg 1996;999:267-74.

8. Haas NP, Hoffmann RF, Mauch C, von Fournier C, Südkamp NP. The management of polytraumatized patients in Germany. Clin Orthop 1995;318:25-35.

9. Haas NP. Recommendations for structures, organization and outfitting preclinical and clinical patient care in trauma surgery departments of German hospitals. Unfallchirurg 1997;100:2-7.

10. ACS. Resources for optimal care of the injured patients. American College of Surgeons, Chicago, 1995.

11. BG. BG-Statistiken für di Praxis, 1993.

12. MacKenzie EJ, Morris JA Jr, Smith GS, Fahey M. Acute hospital costs of trauma in the United States: implications for regionalized systems of care. J Trauma 1990;30:1096-101.

13. Statistisches Jahrbuch für die Bundesrepublik Deutschland, 1991.

14. Schaefer A, Neugebauer E, Bouillon B, Tiling T, Troidl H. Instruments for measuring the quality of life of severely injured patients. Unfallchirurg 1994;97:223-9.

15. Ruchholtz S, Nast-Kolb D, Waydhas C, et al. Cost analysis of clinical treatment of polytrauma patients. Chirurg 1995;66:684-92.

16. Kinzl L. Polytraumakosten, 1996.

17. Obertacke U, Neudeck F, Wihs HL, Schmit-Neuerberg KP. Cost analysis of primary care and intensive care treatment of multiple trauma patients. Unfallchirurg 1997;100:44-9.

18. Strassenverkehrsunfallbilanz 1999 (2000). Internet: http://www.statistik-bund.de (accessed 20th December 2000). 